Case Report

\title{
Recurrent collaural fistula: a challenge
}

\author{
Shashikant Anil Pol*, Surinder K. Singhal, Nitin Gupta, Shalima Pulpra Sivanandan
}

Department of ENT and Head \& Neck Surgery, GMCH, Chandigarh, UT, India

Received: 07 June 2019

Accepted: 02 August 2019

\section{*Correspondence:}

Dr. Shashikant Anil Pol,

E-mail: drshashikantpol@gmail.com

Copyright: () the author(s), publisher and licensee Medip Academy. This is an open-access article distributed under the terms of the Creative Commons Attribution Non-Commercial License, which permits unrestricted non-commercial use, distribution, and reproduction in any medium, provided the original work is properly cited.

\begin{abstract}
Collaural fistula or cervico-aural fistula is a rare anomaly accounting for less than $8 \%$ of first branchial cleft anomaly. Aberrant development of first branchial cleft may lead to formation of a cervical cyst or sinus in the region of ear. We reported a case of a 4 year old girl who presented with recurrent swelling in right infra-auricular region from 6 months of age. She had undergone incision and drainage of the swelling three times at various peripheral hospitals over past 3.5 years. On examination two sinuses were noticed surrounding lobule of right pinna of which one was present posterior to the lobule and second was present just above lobule at lateral most part of conchal cartilage. Diagnosis of recurrent infected collaural fistula requires detailed clinical examination for presence of multiple sinuses surrounding the lobule and external auditory canal. In case of non visibility of sinus in external auditory canal, microscopic examination should be done. CT sonogram and MRI are useful diagnostic tools for recurrent infected fistulas. Surgical excision of whole tract is the definitive treatment but superficial parotidectomy along with it can reduce chances of recurrence significantly. If more than $30 \%$ of the circumference of external auditory canal is involved then split skin grafting is required for the coverage. Diagnosis of collaural fistula should be kept in mind whenever there is recurrent postaural or infra-aural swelling mainly in paediatric patients. Superficial parotidectomy along with complete excision reduces the recurrence rate. Facial nerve palsy can be a devastating complication of surgery.
\end{abstract}

Keywords: Branchial cleft, Collaural fistula

\section{INTRODUCTION}

During development of human embryo, six branchial arches appear as bar in the wall of pharynx at around $4^{\text {th }}$ week which will form future lower face and neck. ${ }^{1}$ Branchial pouches and cleft develop medially and laterally respectively in between the arches. The external auditory canal develops from dorsal part of first branchial cleft. Ventral part usually disappears but if it persists, may present as anomalies like preauricular sinus or collaural fistula etc. Collaural fistula account for less than 8 percent of all branchial cleft anomali. Failure to recognize these unusual cases may lead to misdiagnosis, inadequate treatment and subsequent recurrence. ${ }^{2}$ Recurrent collaural fistula is managed definitely by surgical exploration and excision once the acute infection is settled.

\section{CASE REPORT}

A 4 year old female child presented with chief complaints of fever, right infra-auricular swelling since two weeks. She had a history of discharge from external opening on the right postaural region and associated recurrent swelling on and off over right infra-auricular region from 6 months of age. First episode of swelling was 2 years back and second was 6 months back. She had undergone incision and drainage of the swelling three times at various peripheral hospitals over past 3.5 years. She was symptomless in between the attacks with persistence of two external openings surrounding the right lobule. CT sinogram done in periphery almost showed an opacifying small linear blind ending tract for a distance of approximately $7.4 \mathrm{~mm}$ from the skin surface without any communication with the underlying structures. 


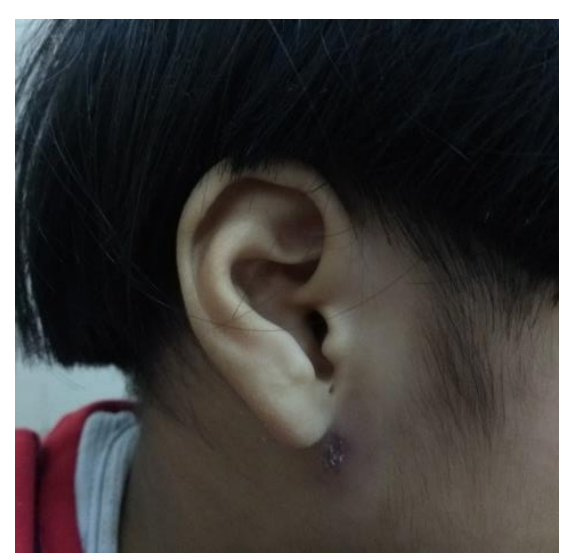

Figure 1: Two openings one above the lobule and another below it.

On local examination, there was local rise in temperature and tenderness was present. Two sinuses were noticed surrounding lobule of right pinna. One opening was present posterior to the lobule and second was found just above lobule at lateral most part of conchal cartilage (Figure 1).

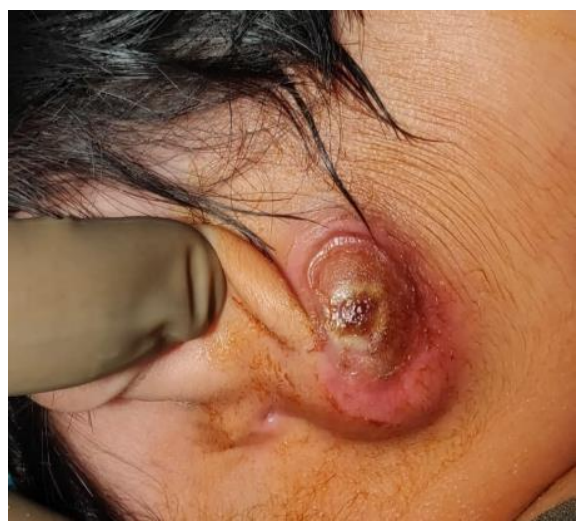

Figure 2: Cystic swelling over right infra-auricular area.

A single swelling $2 \times 2 \mathrm{~cm}$ was present on right infraauricular area, which was soft, fluctuant, tender with pus discharge coming from it (Figure 2). The child was admitted for intravenous antibiotics for acute infection. About $5 \mathrm{ml}$ pus was drained in OT. Examination under microscope was done for external auditary canal which showed no opening or sinus. Tympanic membrane was found intact. The child underwent conservative management with antibiotics, regular aseptic dressing and was discharged after achieving complete recovery of acute infection. CEMRI of temporal bones was done after a week of resolution of infection which showed an ill margined localised phlegmonous soft tissue/inflammation in the subcutaneous fat of right infra-auricular region measuring $24 \times 22 \times 14 \mathrm{~mm}$. There are two thin approximately 1-2 mm, curvilinear tracts leading up to the skin in infra-auricular and retro-auricular regions measuring approximately $1 \mathrm{~cm}$ in length. The soft tissue is abutting the parotid gland on deeper aspect with mild adjacent inflammation of its superficial lobe. She was on regular follow up. After complete recovery of the infection she was planned to undergo excision of the fistula with right superficial parotidectomy to avoid any possibility of recurrence (Figure 3). Under general anaesthesia, modified blair incision with elliptical rim around sinuses was made. 3 tracts were present. One below the right ear lobule, one behind the right ear lobule, and one in front of the right ear lobule. The tract which was below the right ear lobule was going parallel to floor of cartilaginous external auditory canal with duplication of canal and reaching upto osteocartilaginous junction mainly along the floor. This whole tract was removed. Right facial nerve trunk was identified and superficial lobe of parotid was removed along with the tract preserving the facial nerve. Negative suction drain number 10 was inserted and secured. Wound closed in 2 layers-inner vicryl and outer silk. Parotid dressing was done.

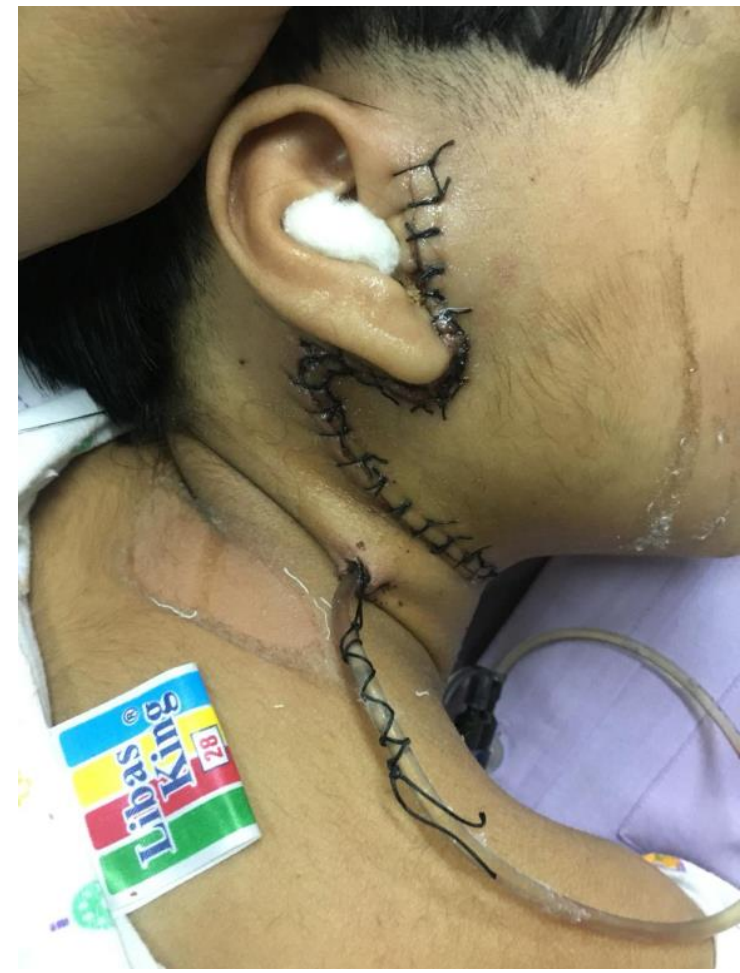

Figure 3: Closure with negative drain in situ.

The child was sent home after drain removal on $4^{\text {th }}$ postoperative day. Suture removal was done on day 7 . Child is on 1 month follow up now and is doing well.

\section{DISCUSSION}

First branchial cleft anomalies develop due to incomplete obliteration of the cleft between the mandibular process of the first arch and the second arch. It can be sinus or fistula. A sinus will have an opening in the upper neck or in the floor of external auditory canal, wheras a fistula will have opening in both of these sites. Work has classified first branchial cleft anomalies into 2 types; type 
1 or type $2 .^{3}$ Type 1 is duplication of cartilaginous external auditory canal in which a post-auricular cystic mass extends medially and anteriorly along external auditory canal. It is usually lateral to facial nerve and ends at bony meatus. Type 2 is duplication of cartilaginous external auditory canal and pinna. A sinus passes from an external opening in the neck along anterior border of sternocleidomastoid muscle, superficial or deep to the facial nerve in relation to the parotid. It can either end blindly at floor of cartilaginous external auditory canal or open into canal called collaural fistula. In this patient it was type 1 tract which was lying lateral to the facial nerve. Diagnosis of recurrent infected collaural fistula requires detailed clinical examination for presence of multiple sinuses surrounding the lobule and external auditory canal. In case of non visibility of sinus in external auditory canal microscopic examination should be done. CT sinogram and MRI are useful diagnostic tools for recurrent infected fistulas. The high resolution $\mathrm{CT}$ imaging shows its exact relationship with the EAC and the middle ear. ${ }^{4}$ Surgical excision of whole tract is the definitive treatment with resection of a small amount of skin and cartilage within external auditory meatus. ${ }^{5}$ A conservative superficial parotidectomy with full exposure of facial nerve is required to avoid damage to the facial nerve and can also reduce chances of recurrence significantly. ${ }^{6}$ If more than $30 \%$ of the circumference of external auditory canal is involved then split skin grafting is required for the coverage.

\section{CONCLUSION}

Branchial cleft may present as cysts, sinuses or fistulous tracts, which are pre-auricular, post-auricular or high in the neck. Diagnosis of collaural fistula should be kept in mind whenever there is recurrent postaural or infra-aural swelling mainly in paediatric patients. Superficial parotidectomy along with complete excision of tract reduces the recurrence rate significantly. Facial nerve palsy can be a devastating complication of surgery.

Funding: No funding sources

Conflict of interest: None declared

Ethical approval: Not required

\section{REFERENCES}

1. Sokroos RJ, Manni JJ. The double auditory meatusrare first branchial cleft anomaly clinical presentation and treatment. Am J Otol. 2002;21:837-41.

2. Whetsone J, Branstetter BF. Flouroscopic and CT fistulography of the first branchial cleft. Am J Neuroradiol. 2006;27:1817-9.

3. Coppens F, Peene P, Lemahieu SF. Diagnosis and differential diagnosis of branchial cleft cysts by CT scan.journal Belge de Radiologie.1990;73(3):18996.

4. Siechel JY, Halperin D, Dano I, Dangoor E. Clinical update on type 2 first branchial cleft cysts. Laryngoscope. 1998;108:1524-7.

5. Hu YJ, Li YD, Qu XZ, Wang LZ, Zhong LP, Liu L, Zhang CP. Clinical analysis of branchial cleft cyst (fistula): Report of 284 cases. 2008;17(5):461-4.

6. Choi JH, Woo HY. Two cases of first branchial cleft anomalies medial to the facial nerve. J Curr Surg. 2012;2:29-31.

Cite this article as: Pol SA, Singhal SK, Gupta N, Sivanandan SP. Recurrent collaural fistula: a challenge. Int J Otorhinolaryngol Head Neck Surg 2019;5:1404-6. 